\title{
Incidence and Predictors of Contrast-induced Nephropathy in Patients Undergoing Percutaneous Coronary Interventions at an Indian Tertiary Care Center
}

\author{
MANEESHA SASIDHARAN, E. JAMES* AND J. C. MENON ${ }^{1}$ \\ Department of Pharmacy Practice, Amrita School of Pharmacy, ${ }^{1}$ Department of Adult Cardiology, Amrita Institute of Medical \\ Sciences, Amrita Vishwa Vidyapeetham, AIMS Health Science Campus, Ponekkara, Kochi-682 041, India
}

\author{
Sasidharan et al.: Contrast-induced nephropathy in PCI patients
}

\begin{abstract}
This investigation is aimed to assess the incidence and possible risk factors of contrast-induced nephropathy and also the utility of Mehran risk score for prediction of contrast-induced nephropathy in patients undergoing percutaneous coronary interventions. A cross-sectional observational study was conducted on 480 patients who underwent percutaneous coronary interventions. Patients with and without contrastinduced nephropathy were evaluated to recognize the predictive factors of contrast-induced nephropathy and explored the benefit of Mehran's risk score for prediction of contrast-induced nephropathy using receiver operating characteristics curve, Youden's index and a likelihood ratio test. The incidence of contrast-induced nephropathy was $5.2 \%$ (95\% confidence interval- 4.75 to 5.65). The associated risk factors were diabetes mellitus, hypertension, age $>75$ years and contrast volume $\geq 100 \mathrm{ml}$ ( $p>0.001)$. Multivariate analysis identified age $>75$ years and hypertension as independent risk factors. Low Mehran risk category (score $<5$ ) patients had a higher occurrence (56\%) of contrast-induced nephropathy compared to other Mehran risk groups. Mehran risk scoring had high sensitivity (63.1\%) and low specificity (44 \%), which was affirmed by Youden's index (0.071) and an area under the receiver operating characteristics curve of 0.592. Contrast-induced nephropathy is a possible risk factor for all patients undergoing percutaneous coronary interventions. Contrast volume $\geq \mathbf{1 0 0} \mathrm{ml}$, age $>75$ years, diabetes mellitus and hypertension were the predictors of contrast-induced nephropathy. Mehran risk score appeared irrelevant in stratifying the risk of contrast-induced nephropathy in patients undergoing percutaneous coronary interventions.
\end{abstract}

Key words: Contrast-induced nephropathy, Mehran risk score, percutaneous coronary intervention, sensitivity, specificity

Percutaneous coronary intervention (PCI), a procedure used to open clogged coronary arteries, involves temporary insertion and inflation of a balloon into the stenosed artery in order to widen it. A metallic scaffold, either bare metal or drug eluting, is often inserted during the procedure (coronary stenting) to maintain the patency of the artery and to decrease the chances of restenosis. This intervention needs visualization of the blood vessels by way of injecting a radio-contrast agent during fluoroscopy. The incidence of renal insufficiency is elevated in patients subjected to PCI due to the use of radiographic contrast media in angiographic procedures. Contrast-induced nephropathy (CIN), also known as contrast-induced acute kidney injury (AKI), is a self-generated renal injury that occurs after intra-arterial administration of radio-opaque contrast media ${ }^{[1]}$. The European Society

*Address for correspondence E-mail: emmanuelj@aims.amrita.edu

July-August 2019 of Urogenital Radiology (ESUR) defines CIN as an elevation of serum creatinine of $>25 \%$ or $\geq 0.5 \mathrm{mg} / \mathrm{dl}$ absolute value compared to the baseline within $48-72 \mathrm{~h}$ following the administration of radio-opaque contrast media in the absence of other alternative causes of $\mathrm{AKI}^{[2]}$.

The pathophysiology of CIN identifies that the ascending loop of Henle has an increased exposure to ischemia where oxygen requirement is high due to active sodium re-absorption ${ }^{[3]}$. Following the intra-

This is an open access article distributed under the terms of the Creative Commons Attribution-NonCommercial-ShareAlike 3.0 License, which allows others to remix, tweak, and build upon the work non-commercially, as long as the author is credited and the new creations are licensed under the identical terms

Accepted 21 June 2019

Revised 27 March 2019

Received 27 December 2018

Indian J Pharm Sci 2019;81(4):729-736 
arterial administration of contrast media, the vascular endothelium releases various vasoactive mediators like nitrous oxide, adenosine, endothelin, prostaglandins, and reactive oxygen species (ROS) causing imbalance leading to vasoconstriction ${ }^{[4]}$. The ischemic tissue further releases more toxic vasoactive mediators thus extending the duration of vasoconstriction. The increased viscosity and hyperosmolality of the contrast media cause further reduction in medullary blood flow ${ }^{[3]}$. As the contrast media is filtered and concentrated within the tubules, there will be an increase in viscosity causing tubular block, which when combined with the release of ROS result in acute renal tubular injury. Thus a combination of cytotoxicity, prolonged vasoconstriction and increase in viscosity leads to initiation of medullary ischemia ${ }^{[5]}$.

Reported incidence of CIN varies ( $<2$ to $30 \%$ ) depending up on the study population, the prevalence of associated risk factors and the definition of $\mathrm{CIN}^{[3,6-8]}$. Patients undergoing coronary angiography or PCI have the highest CIN incidence compared to other procedures using contrast media for diagnostic or therapeutic purposes. Similarly, patients with underlying risk factors have a high incidence of CIN. Few risk scoring scales ${ }^{[9-11]}$ were developed to predict CIN risk, but none have been adequately validated. Relevance of Mehran risk scoring ${ }^{[10]}$ for prediction of CIN risk has been recently questioned ${ }^{[12]}$ and the CIN consensus working panel ${ }^{[13]}$ does not currently recommend it for CIN prediction. Hence our objectives were to assess the incidence and risk factors of CIN in patients undergoing PCI in a tertiary care centre and to determine the predictive value of Mehran risk score in assessing CIN.

\section{MATERIALS AND METHODS}

A cross-sectional observational study was carried out on adult patients admitted to the coronary care unit of a tertiary care hospital (AIMS, Kochi) for diagnostic or therapeutic PCI during September 2017 to February 2018. Patients who gave informed signed consent and who had a serum creatinine measurement prior to contrast administration and 24-48 $\mathrm{h}$ after the coronary intervention were eligible for the study. Patients receiving long term peritoneal and haemodialysis, patients with a previous episode of acute kidney injury, patients who died during PCI, who underwent renal intervention, who were allergic to radio contrast media, and patients with incomplete data were excluded. The study was approved by Institutional Ethics Committee (IEC) of AIMS (IEC-AIMS-2017PHARM-361, September 17, 2017). The flow chart of the study process is shown in fig. 1. CIN was defined as an increase in serum creatinine concentration of

Patient's undergone coronary intervention during the prospective study period

$(n=499)$

Patients enrolled and completed evaluation

Excluded (n=19)

- Undergoing hemodialysis $(\mathrm{n}=3)$

- Incomplete patient file $(n=8)$

- Denied informed consent $(\mathrm{n}=6)$

- Previous episode of AKI $(n=2)$

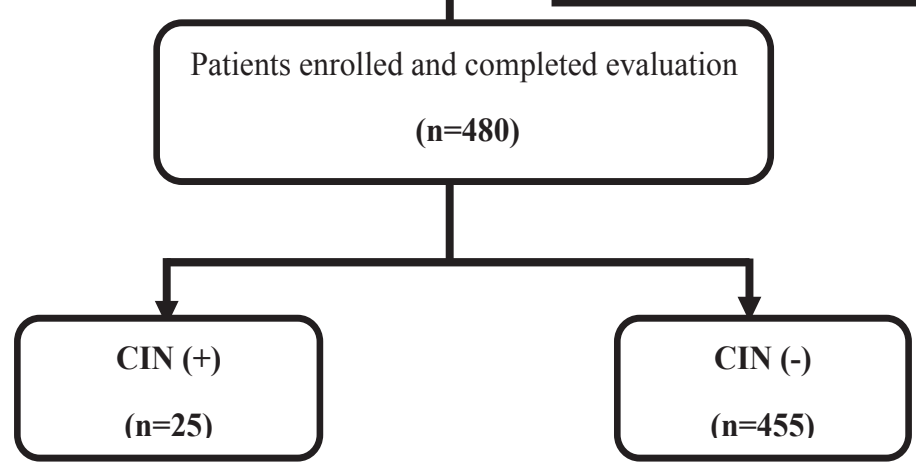

Fig. 1: Flow chart of the study process

CAG- coronary angiogram, PTCA- percutaneous transluminal coronary angioplasty, CIN- contrast-induced nephropathy, AKI- acute kidney injury 
$\geq 0.5 \mathrm{mg} / \mathrm{dl}$ or $25 \%$ above baseline within $48-72 \mathrm{~h}$ after contrast administration as per ESUR ${ }^{[2]}$. Anemia was defined as a haematocrit value of $<39 \%$ in men and $<36 \%$ in females. Hypotension was defined as a systolic blood pressure of $<80 \mathrm{mmHg}$ for at least $1 \mathrm{~h}$ with requirement of inotropic support.

Serum creatinine concentration was measured 6-12 h prior to the procedure and was repeated post PCI during the hospital stay. The glomerular filtration rate (GFR) was calculated using modification of diet in renal disease equation ${ }^{[14]}$. Medications such as metformin, angiotensin converting enzyme inhibitors, angiotensin receptor blockers, non-steroidal antiinflammatory agents, and aminoglycosides were withheld from patients prior to PCI and restarted $24-48 \mathrm{~h}$ post PCI. Most of the patients received hydration with normal saline or dextrose 6-12 h pre and post-procedure as well as $\mathrm{N}$-acetylcysteine $600 \mathrm{mg}$ twice daily for 6 doses at $12 \mathrm{~h}$ intervals. Charlson co-morbidity index (CCI) of the patients was calculated using an online calculator. The CIN risk was predicted using Mehran risk prediction scale ${ }^{[10]}$. The tri-iodinated nonionic lowosmolar radiocontrast media iohexol (Omnipaque ${ }^{\circledR}$ manufactured by GE Healthcare (Shanghai Co., Ltd, China) or non-ionic iso-osmolar radiocontrast media iodixanol (Visipaque ${ }^{\circledR}$ manufactured by GE Healthcare (Shanghai Co., Ltd, China) were the contrast media used.

Statistical analysis was carried out using IBM statistical package for social sciences (SPSS) version 20 for windows. Categorical data were reported as percentages and absolute values and continuous data were expressed as mean values \pm standard deviation. Comparison between groups of categorical variables such as sex, smoking, co-morbidities, nephrotoxic drugs, contrast type, catheter insertion site, CIN risk categories, CIN (+) and CIN (-) were made using Chi square test whereas student's t- test was employed for comparison between groups of continuous variables like height, weight, body mass index, age, laboratory values, fluoroscopy time, contrast volume, duration of hospital stay, and CCI score. A p value $<0.05$ was considered as significant. Reliability of Mehran's score in predicting CIN was tested by determining the sensitivity, specificity, positive predictive value and negative predictive value of Mehran risk scoring. Positive likelihood ratio, negative likelihood ratio, Youden's index, and ROC curve were also determined in order to evaluate the risk prediction scale.

\section{RESULTS AND DISCUSSION}

Out of the 499 patients who underwent coronary intervention, 480 were included in the study. Among these, 25 patients developed CIN (fig. 2) with an incidence of $5.2 \%$ (95\% confidence interval (CI)4.75-5.65). The incidence of CIN associated with PCI in our patients was higher than that reported by Kumar et $a l .{ }^{[15]}$ from Pune, India where an overall CIN incidence of $2.4 \%$ was observed. They included PCI patients with normal renal parameters and excluded patients with risk of CIN such as known chronic kidney disease (stage 5), baseline creatinine $>1.5 \mathrm{mg} / \mathrm{dl}$, significant hypotension, anaemia and patients with myocardial infarction. Another study by Valappil et al. ${ }^{[6]}$ from Trivandrum, Kerala found a CIN incidence of $29 \%$ where they included only patients with impaired renal function (GFR of 30-60 ml/min/ $1.73 \mathrm{~m}^{2}$ ) and excluded patients with ST elevated myocardial infarction and cardiogenic shock as well as patients undergoing haemodialysis or peritoneal dialysis. These inconsistencies of inclusion and exclusion criteria may be a reason for the variability in incidence of CIN as both the studies used the same definition of CIN as ours. A prospective study conducted at Chennai by Victor et al. ${ }^{[7]}$ found a CIN incidence of $9.7 \%$ where the inclusion and exclusion criteria were similar to our study.

Males were predominant among the global patients $(332 / 480,69.1 \%)$ as well as among patients with CIN (17/25, 68\%) and without CIN (316/455, 69.2\%). Mean age of patients with CIN was $61.40 \pm 13.86 \mathrm{y}$ (median- $63 \mathrm{y}$, range- 26-79 y) and for those without $\mathrm{CIN}$, the mean age was $60.55 \pm 10.13$ y (median-

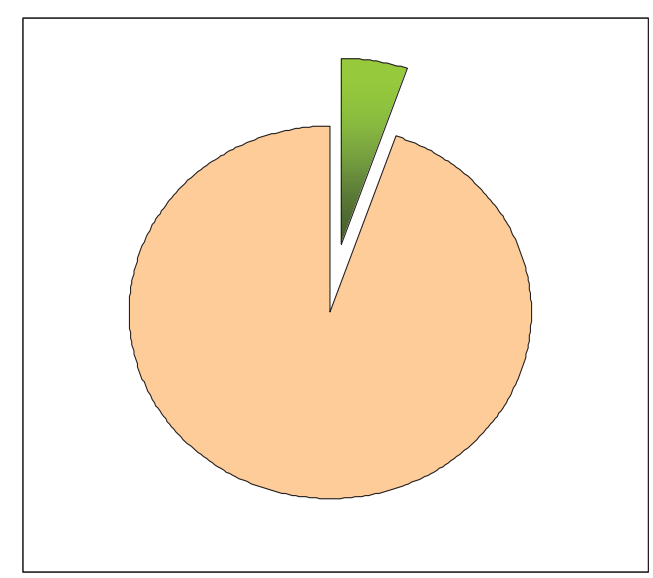

Fig. 2: Incidence of CIN in study patients after percutaneous coronary intervention

a Patients with CIN (5.2 \%); patients without CIN (94.8\%); CIN- contrast-induced nephropathy 
TABLE 1: BASELINE SOCIO-DEMOGRAPHIC AND CLINICAL CHARACTERISTICS OF STUDY PATIENTS WITH AND WITHOUT CIN

\begin{tabular}{|c|c|c|c|c|c|c|c|}
\hline \multirow{2}{*}{ Patient characteristics } & \multicolumn{2}{|c|}{ Global population $(n=480)$} & \multicolumn{2}{|c|}{$\mathrm{CIN}(+)(\mathrm{n}=25)$} & \multicolumn{2}{|c|}{ CIN (-) $(n=455)$} & \multirow[b]{2}{*}{$p$ value } \\
\hline & No. & $\%$ & No. & $\%$ & No. & $\%$ & \\
\hline Age $>75$ y & 38 & 7.9 & 6 & 24 & 32 & 7 & $0.002 * *$ \\
\hline Males & 332 & 69.1 & 17 & 68 & 315 & 69.2 & 0.897 \\
\hline Smokers & 232 & 48.3 & 12 & 48 & 220 & 48.4 & 0.973 \\
\hline Diabetes mellitus & 229 & 47.7 & 17 & 68 & 212 & 46.5 & $0.037^{* *}$ \\
\hline Hypertension & 269 & 56.0 & 19 & 76 & 250 & 55 & $0.039 * *$ \\
\hline Dyslipidemia & 211 & 43.9 & 12 & 48 & 199 & 44 & 0.676 \\
\hline Anemia* & 116 & 24.1 & 6 & 24 & 110 & 24.1 & 0.979 \\
\hline $\mathrm{CHF}^{\dagger}$ & 30 & 6.2 & 3 & 12 & 27 & 6 & 0.222 \\
\hline Hypotension ${ }^{\ddagger}$ & 8 & 1.6 & 0 & 0 & 8 & 1.7 & 0.457 \\
\hline Mean BMI $\left(\mathrm{kg} / \mathrm{m}^{2}\right) \pm \mathrm{SD}$ & \multicolumn{2}{|c|}{$24.37 \pm 3.51$} & \multicolumn{2}{|c|}{$24.21 \pm 2.92$} & \multicolumn{2}{|c|}{$24.54 \pm 4.11$} & 0.523 \\
\hline
\end{tabular}

${ }^{*}$ Male- haematocrit value $<0.39$, female- haematocrit value $<0.36$, ${ }^{\dagger}$ New York Heart Association Class IV heart failure, ${ }^{\ddagger}$ systolic blood pressure $<80 \mathrm{mmHg}$ for hypotension. ${ }^{*}$ Statistically significant. BMI- body mass index, SD- standard deviation, CHF- congestive heart failure, CIN (+)patients with contrast-induced nephropathy, CIN (-)-patients without contrast-induced nephropathy

TABLE 2: CLINICAL CHARACTERISTICS AND PROCEDURE RELATED VARIABLES OF STUDY PATIENTS

\begin{tabular}{|c|c|c|c|c|}
\hline Clinical parameters & $\begin{array}{c}\text { Global population } \\
(n=480)\end{array}$ & With CIN (n=25) & $\begin{array}{l}\text { Without CIN } \\
(n=455)\end{array}$ & $p$ value \\
\hline Mean serum creatinine (baseline, $\mathrm{mg} / \mathrm{dl}$ ) $\pm \mathrm{SD}$ & $1.02 \pm 0.46$ & $0.98 \pm 0.26$ & $1.07 \pm 0.67$ & 0.682 \\
\hline Mean serum creatinine (After $48 \mathrm{~h}, \mathrm{mg} / \mathrm{dl}) \pm \mathrm{SD}$ & $1.12 \pm 0.47$ & $1.23 \pm 0.37$ & $1.02 \pm 0.58$ & 0.683 \\
\hline Mean eGFR (baseline, mg/dl) \pm SD & $78.28 \pm 22.21$ & $83.30 \pm 27.75$ & $78.00 \pm 21.87$ & 0.191 \\
\hline Mean eGFR (after $48 \mathrm{~h}, \mathrm{mg} / \mathrm{dl}) \pm \mathrm{SD}$ & $98.57 \pm 379.75$ & $65.53 \pm 23.78$ & $78.00 \pm 21.87$ & 0.754 \\
\hline Mean fluroscopy time (min) $\pm S D$ & $19.43 \pm 64.71$ & $30.27 \pm 119.34$ & $8.6 \pm 10.08$ & 0.374 \\
\hline Mean contrast volume $(\mathrm{ml}) \pm \mathrm{SD}$ & $114.05 \pm 52.13$ & $152.80 \pm 28.97$ & $75.3 \pm 28.97$ & 0.541 \\
\hline Mean LVEF $(\%) \pm$ SD & $54.39 \pm 10.05$ & $53.47 \pm 10.44$ & $55.31 \pm 9.67$ & 0.340 \\
\hline $\begin{array}{l}\text { Contrast volume } \\
\geq 100 \mathrm{ml} \text {, no. (\%) }\end{array}$ & $128(26.6)$ & $25(100)$ & $103(22.6)$ & $<0.001^{* *}$ \\
\hline ACEI use, no. (\%) & $8(1.6)$ & $1(4)$ & $7(1.5)$ & 0.349 \\
\hline ARB use, no. (\%) & $59(12.2)$ & $3(12)$ & $56(12.3)$ & 0.964 \\
\hline \multicolumn{5}{|l|}{ Location of culprit artery (No. (\%) } \\
\hline $\begin{array}{l}\text { - Left main artery } \\
\text { - LAD } \\
\text { - Circumflex } \\
\text { - Right coronary }\end{array}$ & $\begin{array}{c}77(16.5) \\
218(45.4) \\
39(8.1) \\
146(30.4)\end{array}$ & $\begin{array}{l}6(24) \\
9(36) \\
5(20) \\
5(20)\end{array}$ & $\begin{array}{c}71(15.6) \\
209(45.9) \\
34(7.5) \\
141(30.9)\end{array}$ & 0.070 \\
\hline
\end{tabular}

CIN- contrast-induced nephropathy, SD- standard deviation, CHF- congestive heart failure, LVEF- left ventricular ejection fraction, eGFRestimated glomerular filtration rate, ACEI- angiotensin converting enzyme inhibitor, ARB- angiotensin receptor blocker. LAD- left anterior descending, ${ }^{* *}$ statistically significant

$61 \mathrm{y}$, range- 23-86 y). The baseline demographical and social characteristics of the patients with and without CIN are shown in Table 1 and clinical characteristics and procedure related variables of study patients are shown in Table 2. CIN was observed to be more common in patients with risk factors like hypertension (19/25, $76 \%)$, diabetes mellitus $(17 / 25,68 \%)$, patients who received $\geq 100 \mathrm{ml}$ of contrast media $(25 / 25$, $100 \%, \mathrm{p}<0.001)$ and those with age $>75$ y $(6 / 25$, $24 \%$ ). Other previously reported risk factors ${ }^{[15,16]}$ such as hypotension, dyslipidaemia, anaemia, chronic heart failure and pre-existing renal impairment were not significant in our study patients. Higher the baseline serum creatinine, higher would be the risk of CIN, but not in patients with mild decrease in renal function.
In our study, the mean pre-procedural baseline serum creatinine was $0.98 \pm 0.26 \mathrm{mg} / \mathrm{dl}$ in the $\mathrm{CIN}(+)$ group and $1.07 \pm 0.67 \mathrm{mg} / \mathrm{dl}$ in the CIN (-) group whereas, the post-procedural mean serum creatinine was $1.23 \pm$ $0.37 \mathrm{mg} / \mathrm{dl}$ and $1.02 \pm 0.67 \mathrm{mg} / \mathrm{dl}$ in the CIN (+) and CIN (-) group, respectively and there was no significant association of CIN with baseline serum creatinine. The results of our study were comparable to a study by Pérez et al ${ }^{[16]}$ from Mexico in which similar creatinine levels pre and post-PCI were reported. None of our patients required haemodialysis after PCI.

Even though, 39.6\% (190/480) of patients had a history of statin use, $40 \%(10 / 25)$ of them developed CIN and prior statin use had no significant association with CIN in our patients. But, studies ${ }^{[17,18]}$ have suggested 
that chronic use of statins have a preventive effect on $\mathrm{CIN}$ and a beneficial effect in reducing the incidence of dialysis and long-term mortality. Of 466/480 (97.1\%) patients who underwent PCI via trans-radial access, 25 developed CIN whereas none of those who underwent PCI via trans-femoral access had a CIN incidence $(p=0.654)$. Since none of our patients who underwent PCI via trans-femoral access developed CIN, the trans-femoral access for PCI may reduce the incidence of CIN. This reduction in CIN incidence may also be due to the fact that majority $(466 / 480,97.1 \%)$ of our patients underwent PCI through trans-radial approach and further studies with more number of patients via trans-femoral access are needed to confirm the possible association. But a study by Mann et al. ${ }^{[19]}$ compared the radial approach with femoral approach for coronary stenting in patients with acute coronary syndromes in 142 patients and concluded that coronary stenting from radial approach is more efficacious than that via trans-femoral access. Out of 359/480 (74.8 \%) patients who received preventive strategies with either $\mathrm{N}$-acetylcysteine or hydration using normal saline or dextrose, 22/25 (88\%) developed CIN. But, these preventive strategies had no significant association

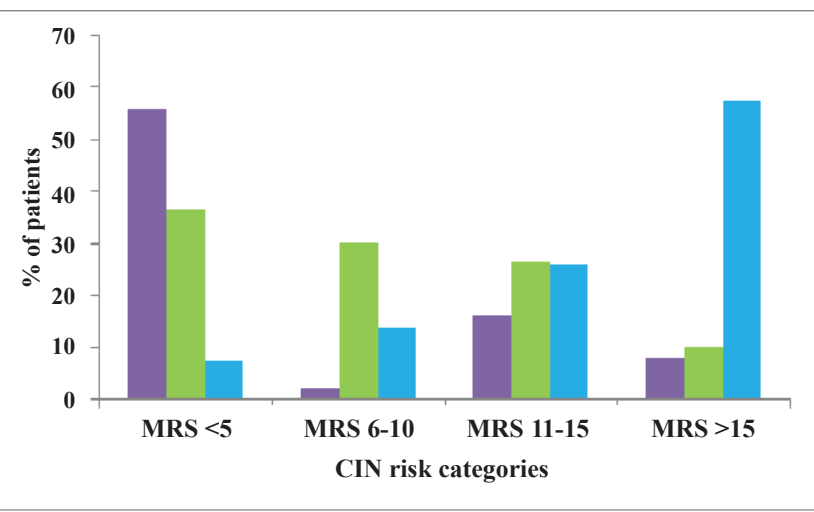

Fig. 3: CIN incidence in various Mehran risk categories CIN incidence in various Mehran risk categories of the current study compared to a French study ${ }^{[12]}$ and Mehran's data च current study; $\square$ Ivans et al. ${ }^{[12]}$; $\square$ Mehran et al. ${ }^{[10]}$; MRSMehran risk score $(p=0.118)$ with CIN in our study. Saline hydration plays a role in intravascular volume expansion and inhibition of rennin-angiotensin-aldosterone pathway ${ }^{[20]}$. A study by Weisbord et al. ${ }^{[21]}$ concluded that peri-procedural intravenous isotonic sodium bicarbonate showed no benefit over intravenous isotonic sodium chloride with respect to the risk of major adverse kidney events, death or AKI. In addition, they found no benefit of oral administration of $\mathrm{N}$-acetylcysteine over placebo in decreasing CIN risk. Other studies ${ }^{[22,23]}$ reported that reduction in effective intravascular volume associated with reduced cardiac output decrease the renal perfusion and increase the risk of CIN in patients with congestive heart failure (CHF) but it was not a significant risk factor in our study, which may be due to lesser number of patients $(30 / 480,6.25 \%)$ with CHF.

In the present study, a CIN risk stratification scoring by Mehran et al. ${ }^{[10]}$ was utilized, a higher score indicating increased risk of CIN. The mean Mehran risk score of the study patients was $6.46 \pm 4.94$. But our patients in the very high Mehran risk category (score $>15$ ) had a lower incidence $(2 / 25,8 \%)$ of CIN as compared to patients of high $(4 / 25,16 \%)$, moderate $(5 / 25,20 \%)$ and low (14/25, $56 \%$ ) Mehran risk categories. This discrepancy was also found in another study ${ }^{[12]}$ (fig. 3). Majority of our patients $(301 / 480,62.7 \%)$ belonged to low risk category and $56 \%$ (14/25) of them developed CIN while only $8 \%(2 / 25)$ belonging to very high risk category developed CIN. In univariate and multivariate analysis, hypertension and age $>75 \mathrm{y}$ were found to be significant risk factors for the development of CIN. In univariate analysis, the risk factors like diabetes mellitus and use of $\geq 100 \mathrm{ml}$ of contrast media were significantly associated with CIN while, in multivariate analysis, the location of culprit artery had a significant association with development of CIN (Table 3). Out of 8 risk factors of CIN identified by Mehran ${ }^{[10]}$ only three factors, namely, age $>75 \mathrm{y}$, volume of contrast media $>100 \mathrm{ml}$ and diabetes mellitus were predictive of CIN in

TABLE 3: UNIVARIATE AND MULTIVARIATE ANALYSIS OF CIN RISK FACTORS

\begin{tabular}{lcccc}
\hline & \multicolumn{2}{c}{ Univariate analysis } & \multicolumn{2}{c}{ Multivariate analysis } \\
\cline { 2 - 5 } Risk factors & $\mathrm{p}$ value & OR $(\mathrm{Cl})$ & $\mathrm{p}$ value & OR $(\mathrm{Cl})$ \\
\hline Age $>75 \mathrm{y}$ & $<0.001^{* *}$ & $5.21(1.91-14.15)$ & $0.019^{* *}$ & $5.08(1.3-19.81)$ \\
Diabetes mellitus & $0.039^{* *}$ & $2.41(1.02-5.70)$ & $0.037^{* *}$ & 1 \\
Hypertension & $0.041^{* *}$ & $2.57(1.0-6.56)$ & $0.027^{* *}$ & $4.56(1.18-17.58)$ \\
Contrast volume $\geq 100 \mathrm{ml}$ & $<0.001^{* *}$ & $1.24(1.14-1.35)$ & $<0.001^{* *}$ & 1 \\
Location of culprit artery- & & & & \\
- Left main & $0.001^{* *}$ & & & \\
- LAD & 0.727 & & $0.001^{* *}$ & $18.36(3.15-10.86)$ \\
- Circumflex & $0.026^{* *}$ & & 0.727 & $0.80(0.22-2.79)$ \\
\hline
\end{tabular}

OR- odds ratio, $\mathrm{Cl}$ - confidence interval, LAD- left anterior descending, ${ }^{* *}$ statistically significant 
our study patients. Hypertension is not included in the Mehran risk prediction scale. But it was found to have a significant association $(\mathrm{p}=0.039)$ with the occurrence of $\mathrm{CIN}^{[24,25]}$. The role of hypertension in predisposing to CIN can be associated with advanced atherosclerosis of the aorta and may also be due to atheroembolization of the kidney during the coronary intervention ${ }^{[26,27]}$. The Mehran risk score ${ }^{[10]}$ for CIN was proposed for quick identification of the variables and risk allocation but, is not recommended for daily use by the CIN consensus working panel ${ }^{[13]}$, an international multidisciplinary

TABLE 4: RELEVANCE OF MEHRAN RISK SCORE FOR PREDICTION OF CIN

\begin{tabular}{|c|c|c|c|c|}
\hline \multirow[b]{2}{*}{ Parameters } & \multicolumn{4}{|c|}{$\begin{array}{l}\text { Risk category based on Mehran's } \\
\text { score }\end{array}$} \\
\hline & $\begin{array}{l}\text { Low } \\
(0-5)\end{array}$ & $\begin{array}{c}\text { Moderate } \\
(6-10)\end{array}$ & $\begin{array}{c}\text { High } \\
(11-15)\end{array}$ & $\begin{array}{l}\text { Very high } \\
(>15)\end{array}$ \\
\hline $\begin{array}{l}\text { aNo., (\%) of patients } \\
\text { with CIN }\end{array}$ & $14(56)$ & $5(20)$ & $4(16)$ & $2(8)$ \\
\hline Sensitivity (\%) & 63.1 & 31.6 & 5.1 & 0.2 \\
\hline Specificity (\%) & 44 & 80 & 84 & 92 \\
\hline $\begin{array}{l}\text { Positive predictive } \\
\text { value } \\
(\%)\end{array}$ & 95.3 & 96 & 85.2 & 33.3 \\
\hline $\begin{array}{l}\text { Negative predictive } \\
\text { value } \\
(\%)\end{array}$ & 6.1 & 6 & 4.6 & 4.8 \\
\hline Youden's index & 0.071 & 0.116 & -0.109 & -0.078 \\
\hline $\begin{array}{l}\text { Positive likelihood } \\
\text { ratio }\end{array}$ & 1.12 & 1.58 & 0.31 & 0.02 \\
\hline $\begin{array}{l}\text { Negative likelihood } \\
\text { ratio }\end{array}$ & 0.83 & 0.85 & 1.13 & 1.08 \\
\hline
\end{tabular}

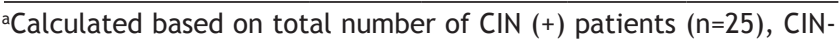
contrast-induced nephropathy

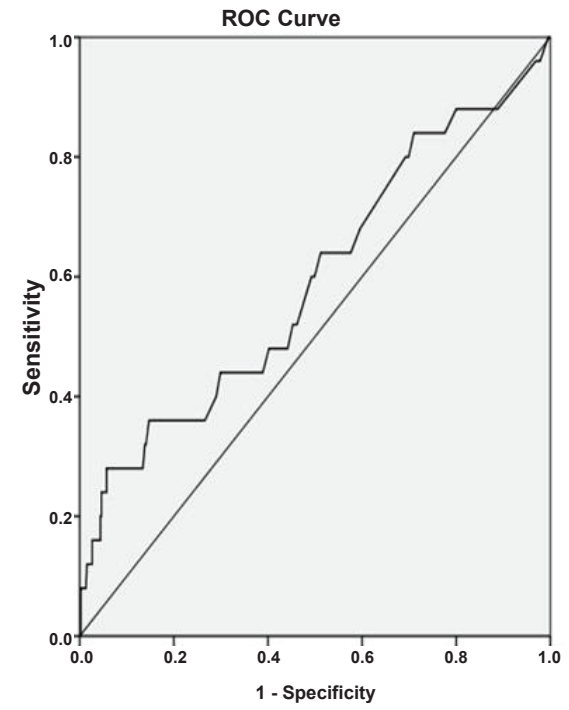

Fig. 4: ROC curve for Mehran's score applied to the study patients

ROC- receiver operating characteristic curve. Diagonal segments are produced by ties 
All the patients $(128 / 480,26.6 \%)$ who received $\geq 100 \mathrm{ml}$ of contrast media in our study developed CIN while none of the patients who received $<100 \mathrm{ml}$ of contrast agent suffered CIN and there was a significant association of CIN with the use of contrast media $\geq 100 \mathrm{ml}$ in our study patients (Table 3 ). The risk of CIN was minimal if the patients received $<100 \mathrm{ml}$ of contrast agent during the procedure ${ }^{[34,35]}$. The initial volume of contrast administered in our study was $30-60 \mathrm{ml}$ and additional volume of contrast was given in case of poor visualization. But, a study by Mekan et al.$^{[36]}$ found that the contrast media-induced reduction in renal function was not significantly higher with a volume of $\geq 100 \mathrm{ml}$. To demonstrate a relationship between the volume of contrast media and the risk of CIN following coronary intervention, further studies are required especially with a larger sample size.

Besides being single centric, our study has the following limitations. Some of our patients with PCI had co-existing cardiac procedures such as aortic valve replacement; atrial septal defect device insertion and the influence of these could not be evaluated. Renal function of some of the patients were monitored only up to $48 \mathrm{~h}$ after PCI due to patient discharge and we could not assess any decrease in renal function during the remaining period in the first week of PCI. This might have resulted in underestimation of CIN.

The incidence of CIN was $5.2 \%$ in our patients undergoing PCI. CIN is a potential risk for all patients having diagnostic or therapeutic procedures with radio contrast media. The risk factors like contrast media volume $\geq 100 \mathrm{ml}$, age $>75 \mathrm{y}$, diabetes mellitus and hypertension were the predictors of CIN in patients undergoing PCI in our study. Mehran risk scoring appeared not relevant in stratifying the CIN risk in PCI patients of our study population.

\section{Acknowledgements:}

Authors are grateful to the patients who gave consent for the study. Authors also thank Dr. Shantikumar V. Nair, Dean Research, Amrita Vishwa Vidyapeetham for motivation in publication of the work.

\section{Conflict of interest:}

Authors have no conflicts of interest

\section{Financial support and sponsorship:}

Nil.

\section{REFERENCES}

1. Rear R, Bell RM, Hausenloy DJ. Contrast- induced nephropathy following angiography and cardiac interventions. Heart 2016;102:638-48.

2. Heyman SN, Rosen S, Khamaisi M, Idée JM, Rosenberger C. Reactive oxygen species and the pathogenesis of radiocontrastinduced nephropathy. Invest Radiol 2010;45:188-95.

3. Sani RN, Eshrangi A, Farokhnejad S. Contrast - induced nephropathy: a review of literature. Rev Clin Med 2015;4:212-5.

4. Bakris GL, Lass N, Gaber AO, Jones JD, Burnett JC Jr. Radio contrast medium induced declines in renal function: A role for oxygen free radicals. Am J Physiol 1990;258:115-20.

5. Heyman SN, Rosen S, Rosenberger C. Renal parenchymal hypoxia, hypoxia adaptation, and the pathogenesis of radiocontrast nephropathy. Clin J Am Soc Nephrol 2008;3:288-96.

6. Valappil SP, Kunjukrishnapillai S, Iype M, Koshy AG, Viswanathan S, Gupta PN, et al. Predictors of contrast induced nephropathy and the applicability of the Mehran risk score in high risk patients undergoing coronary angioplastyA study from a tertiary care centre in South India. Indian Heart J 2017;1279:1-6.

7. Victor SM, Gnanaraj A Vijayakumar S, Deshmukh R, Kandasamy M, Janakirama E, et al. Risk scoring system to predict contrast induced nephropathy following percutaneous coronary intervention. Indian Heart J 2014;66: 517-24.

8. Nough H, Eghbal F, Soltani M, Nejafi F, Falahzadeh H, Fazel H, et al. Incidence and Main Determinants of Contrast - Induced Nephropathy following Coronary Angioplasty or Subsequent Balloon Angioplasty. Cradiorenal Med 2013;3:128-35.

9. Mehran R, Nikolsky E. CIN: Definition, epidemiology and patients at risk. Kidney Int Suppl 2006;69:11-18.

10. Mehran R, Aymong ED, Nikolsky E, Lasic Z, Iakovou I, Fahy $\mathrm{M}$, et al. A simple risk score for prediction of contrast-induced nephropathy after percutaneous coronary intervention: Development and initial validation. J Am Coll Cardiol 2004;44:1393-9.

11. Taher HSE, Hassan AKM, Dimitry SR, Mahfouz AK. Predicting CIN post coronary intervention: A prospective cohort study. Egypt Heart J 2015;67:337-43.

12. Ivanes F, Isorni MA, Halimi JM, Fauchier L, Saint Etienne C, Babuty D, et al. Predictive factors of contrast - induced nephropathy in patients undergoing primary coronary angioplasty. Arch Cardiovasc Dis 2014;107:424-32.

13. Tumlin J, Stacul F, Adam A, McCullough PA. CIN Consensus Working Panel: Pathophysiology of contrast-induced nephropathy. Am J Cardiol 2006;98:14-20.

14. Imai E, Horio M, Nitta K, Yamagata K, Iseki K, Hara S, et al. Estimation of glomerular filtration rate by the MDRD study equation modified for Japanese patients with chronic kidney disease. Cli Exp Nephrol 2007;11;41-50.

15. Kumar S, Nair RK, Aggarwal N, Abbot AK, Muthukrishnan J, Kumar H. Risk Factors for Contrast-Induced Nephropathy after Coronary Angiography. Saudi J Kidney Dis Transpl 2017;28:318-24.

16. Pérez-Topete SE, Miranda-Aquino T, Gasca-Luna K, GuerraVilla MN, Elizondo-Adamchik HE. Contrast-induced nephropathy in patients undergoing percutaneous coronary intervention. Rev Mex Cardiol 2016;27:64-70.

17. Zhang T, Shen LH, Hu LH, He B. Statins for the prevention of Contrast-induced nephropathy: A systematic Review and Meta-analysis. Am J Nephrol 2011;33:344-51. 
18. Kandula P, Shah R, Singh N, Markwell SJ, Bhensdadia $\mathrm{N}$, Navaneethan SD. Statins for prevention of contrastinduced nephropathy in patients undergoing non-emergent percutaneous coronary intervention. Nephrology 2010;15:16570.

19. Mann T, Cubeddu G, Bowen J, Schneider JE, Arrowood M, Newman WN, et al. Stenting in Acute Coronary Syndromes: A Comparison of Radial versus Femoral Access Sites. J Am Coll Cardiol 1998;32:572-76.

20. Mueller C, Buerkle G, Buettner HJ, Petersen J, Perruchoud AP, Eriksson U, et al. Prevention of contrast media-associated nephropathy: Randomized comparison of 2 hydration regimens in 1620 patients undergoing coronary angioplasty. Arch Intern Med 2002;162:2203-09.

21. Weisbord SD, Gallagher M, Jneid H, Garcia S, Cass A, Thwin SS, et al. Outcomes after Angiography with Sodium Bicarbonate and Acetylcysteine. N Engl J Med 2017;10:1-12.

22. Shoukat S, Gowani SA, Jafferani A, Dhakam SH. Contrastinduced Nephropathy in patients Undergoing Percutanous Coronary Intervention. Cardiol Res Pact 2010;2010:1-12.

23. Marenzi G, Lauri G, Assanelli E. Contrast-induced nephropathy in patients undergoing primary angioplasty for acute myocardial infarction. J Am Coll Cardiol 2004;44:178085.

24. Rudnick MR, Berns JS, Cohen RM, Goldfarb S. Nephrotoxic risk of renal angiography: contrast media associated nephrotoxicity and atheroembolism - a critical review. Am J Kidney Dis 1994;24:713-27.

25. Barrett BJ, Parfrey PS. Prevention of nephrotoxicity induced by radiocontrast agents. N Engl J Med 1994;331:1449-50.

26. Nikolsky E, Mehran R, Lasic Z, Mintz GS, Lansky AJ, $\mathrm{Na} \mathrm{Y}$, et al. Low hematocrit predicts contrast-induced nephropathy after percutaneous coronary interventions. Kidney Int 2005;67:706-13.

27. Gruberg L, Dangas G, Mehran R, Mintz GS, Kent KM,
Pichard AD, et al. Clinical outcome following percutaneous coronary intervention in patients with chronic renal failure. Cathet Cardiovasc Interv 2002;55:66-72.

28. Sato A, Hoshi T, Kakefuda Y, Harunari T, Watabe H, Hiraya $\mathrm{D}$, et al. Effect of Mehran risk score for the prediction of clinical outcomes after percutaneous coronary intervention. J Cardiol 2015;66:417-22.

29. Silver SA, Shah PS, Chertow GM, Harel S, Wald R, Harel Z. Risk prediction models for contrast-induced nephropathy:systematic review. BMJ 2015;351:h4395.

30. Bern AS. Nephrotoxicity of contrast media. Kidney Int 1989;36:730-40.

31. Guitterez NV, Diaz A, Timmis GC, O'Neill WW, Stevens MA, Sandberg KR, et al. Determination of serum creatinine trajectory in acute contrast nephropathy. J Interv Cardiol 2002;15:349-54.

32. McCullough PA, Wolyn R, Rocher LL, Levin RN, O’Neill WW. Acute renal failure after coronary intervention: incidence, risk factors, and relationship to mortality. Am J Med 1997;103:368-75.

33. Chalmers N, Jackson RW. Comparison of iodixanol and iohexol in renal impairment. Br J Radiol 1999;72:701-03.

34. Kane GC, Doyle BJ, Lerman A, Barsness GW, Best PJ, Rihal GC. Ultra-low contrast volume reduces rates of contrastinduced nephropathy in patients with chronic kidney disease undergoing coronary angiography. J Am Coll Cardiol 2008;51:89-90.

35. Zachariah G, Harikrishnan S, Krishnan MN, Sanjay PP, Venugopal K, Thankappan KR, et al. Prevalence of coronary artery disease and coronary risk factors in Kerala, South Indian population survey - Design and methods. Indian Heart J 2013;65:243-9.

36. Mekan SF, Rabbani MA, Azhar-Uddin M, Ali SS. Radio contrast nephropathy: is it dose related or not? J Pak Med Assoc 2004;54:372-4. 